\title{
Application of Character Building With Physical Education (CBPE)
}

\author{
Eddy Marheni ${ }^{*}{ }^{1}$, Afrizal S ${ }^{2}$, Eko Purnomo ${ }^{3}$ \\ ${ }^{123}$ Pendidikan Kepelatihan / Fakultas Ilmu Keolahragaan/ Universitas Negeri Padang \\ ${ }^{*}$ Corresponding author, $\equiv$ eddymarheni@fik.unp.ac.id
}

\section{Revisi 07/11/2019; \\ Diterima 03/12/2019 \\ Publish 10/01/2020;}

Kata kunci: Pendidikan

Kejuruan; SMK;

Pendidikan Karakter

\begin{abstract}
Abstrak
Masalah dalam pengabdian ini berupa rendahnya pendidikan karakter pada siswa SMK. Pengabdian ini bertujuan mendeskripsikan karakter yang terbentuk pada mata pelajaran PJOK. Metode yang digunakan adalah demonstrasi dan ceramah. Data dikumpulkan melalui kegiatan observasi dengan bantuan lembar observasi. Selain itu penerapan nilai karakter pada aktivitas jasmani melalui cabang olahraga seperti pencak silat, sepak bola, tarung derajat dan catur secara tidak langsung membiasakan siswa melakukan perbuatan positif atau membentuk karakter positif. Karakter yang terbentuk, yaitu jujur, toleransi, disiplin, kerja keras, kreatif, mandiri, demokratis, rasa ingin tahu, menghargai prestasi, bersahabat/komunikatif, peduli sosial, peduli lingkungan, dan bertanggung jawab. Karakter tersebut merupakan nilai-nilai luhur yang dimiliki oleh bangsa Indonesia yang dapat membekali siswa dalam menghadapi perkembangan IPTEK. Hal ini sejalan dengan keberadaan mata pelajaran PJOK yang sejak awal digunakan untuk menanamkan nilai-nilai moral
\end{abstract}

This is an open access article distributed under the Creative Commons Attribution License, which permits unrestricted use, distribution, and reproduction in any medium, provided the original work is properly cited. (C)2020 by author (s)

\section{PENDAHULUAN}

\section{Analisis Situasi}

Pendidikan karakter adalah sebuah system yang menanamkan nilai-nilai karakter pada peserta didik, yang mengandung komponen pengetahuan, kesadaran individu, tekad, srta adanya kemauan dan tindakan untuk melaksanakan nlai-nilai, baik terhadap Tuhan Yang Maha Esa, diri sendiri, sesama manusia, linkungan, maupun bangsa, sehingga akan terwujud insane kamil (Lilis Rosita, 2018). Pendidikan dengan model pendidikan karakter berorientasi pada pembentukan anak sebagai manusia yang utuh. Kualitas anak didik menjadi unggul tidak hanya dalam aspek kognitif, namun juga dalam karakternya. Anak yang unggul dalam karakter akan mampu menghadapi segala persoalan dan tantangan dalam hidupnya (Sri Judiani. 2010). Tujuan pendidikan yang benar adalah membentuk peserta didik yang cerdas secara intlektual dan berkarakter "Intellegence plus character, that is the true education".

Pendidikan karakter merupakan pendidikan yang dapat mengoptimalkan perkembangan seluruh dimensi anak baik berupa kognitif, fisik, sosial-emosi, kreativitas, dan 
spiritual. Pendidikan dengan model pendidikan karakter berorientasi pada pembentukan anak sebagai manusia yang utuh (Sri Judiani. 2010). Dalam konteks pendidikan, pendidikan karakter dapat dimaknai sebagai pendidikan nilai, pendidikan budi pekerti, pendidikan moral, pendidika $\mathrm{n}$ watak, yang bertujuan mengembangkan kemampuan peserta didik untuk memberikan keputu san baik-buruk, memelihara apa yang baik, dan mewujudkan kebaik-an itu dalam kehidupan se hari-hari dengan sepenuh hati (Kemdiknas, 2010).

Saat ini Indonesia mengalami krisis multi dimensi, diantaranya permasalahanpermasalahan yang timbul di negara indonesia ini adalah penyimpangan moral seperti: seks bebas, tawuran pelajar, kebut-kebutan dijalan oleh para pelajar, pengguna narkoba, minuman keras, perjudian, kasus korupsi, perampokan, bom bunuh diri teroris dll (Rifki Afandi, 2011). Pembangunan karakter bangsa yang sudah diupayakan dengan berbagai bentuk, hingga saat ini belum terlaksana dengan optimal (Deny Setiawan, 2013). Masyarakat Indonesia yang terbiasa dengan kesantunan dalamberperilaku, musyawarah mufakat dalam menyelesaikan masalah, kearifan lokal yang kaya dengan pluralitas, sikap toleran dan gotong-royong, mulai cenderung berubah menjadi hegemoni kelompok-kelompok yang saling mengalahkan dan berperilaku egois individual (Deny Seriawan, 2013).

Istilah karakter berasal dari bahasa Yunani "charassein" yang berarti mengukir, memben tuk karakter diibaratkan seperti mengukir batu permata atau permukaan besi yang keras (Sri Ju diani. 2010). Character kemudian diartikan sebagai tanda atau ciri yang khusus, dan karenanya melahirkan sutu pandangan bahwa karakter adalah pola perilaku yang bersifat individual, kead aan moral seseorang (Ajat Sudrajat. 2011).

Karakter adalah cara berpikir dan berperilaku yang menjadi ciri khas tiap individu untuk hidup dan bekerjasama, baik dalam lingkup keluarga, masyarakat dan negara. Individu yang berkarakter baik adalah individu yang bisa membuat keputusandan siap mempertanggung jawabkan akibat dari keputusan yang dibuatnya (Suyatno, 2009).Karakter adalah watak, tabiat, akhlak, atau juga kepribadian seseorang yang terbentuk dari hasil internalisasi berbagai kebajikan yang diyakini dan mendasari cara pandang, berpikir, sikap, dan cara bertindak orang tersebut. Kebajikan tersebut terdiri atas sejumlah nilai, moral, dan norma seperti jujur, berani bertindak, dapat dipercaya, hormat kepada orang lain (Kemendiknas, 2010). Pengembangan karakter, atau pembinaan kepribadian pada anggota masyarakat, secara teoretis maupun secara empiris, dilakukan sejak usia dini hingga dewasa (Kemendiknas, 2010).

Pendidikan adalah usaha sadar dan terencana untuk mewujudkan suasana belajar dan proses pembelajaran agar peserta didik secara aktif mengembangkan potensi dirinya untuk memiliki kekuatan spiritual keagamaan, pengendalian diri,kepribadian, kecerdasan, akhlak mulia, serta keterampilan yang diperlukan dirinya, masyarakat, bangsa dan negara (Depdiknas, 2003).Pendidikan karakter adalah suatu sistem pendidikan dengan penanaman nilai-nilai sesuai dengan budaya bangsa dengan komponenaspek pengetahuan (cognitive), sikap perasaan (affectionfelling), dan tindakan, baik terhadap Tuhan Yang Maha Esa (YME) baik untuk diri sendiri, masyarakan dan bangsanya (Rifki, 2011).

Pendidikan karakter membina anak didik menjadi warga negara yang baik, yang memiliki pengetahuan, keterampilan dan kepedulian sosial yang berguna bagi dirinya sendiri serta bagi masyarakat dan bagi negara. Untuk merealisasikan tujuan tersebut, proses mengajar dan membelajarkannya, tidak hanya terbatas pada aspek-aspek pengetahuan (kognitif) dan keterampilan (psikomotor) saja, melainkan juga meliputi aspek akhlak (afektif) serta bertanggung jawab sesuai yang terkandung dalam nilai-nilai Pancasila (Nursid Sumaatmadja, 2007). 
Proses penanaman nilai-nilai karakter siswa menurut Krathwohl, Bloom \& Masia (1964) ada 5tahap, yaitu:

1. Receiving (menyimak)

2. Responding (menanggapi)

3. Valuating (member nilai)

4. Organizing (mengorganisasikan nilai)

\section{Characteri-zation}

Pendidikan jasmani merupakan salah satu usaha sadar untuk menciptakan lingkungan yang mampu mempengaruhi potensi peserta didik agar berkembang ke arah tingkah laku yang positif melalui aktivitas jasmani (Bandi Utama. 2011). Aktivitas jasmani inilah bentuk rangsangan yang diciptakan untuk mempengaruhi potensi-potensi yang dimiliki peserta didik dalam pembelajaran pendidikan jasmani di sekolah mulai dari jenjang pendidikan usia dini sampai pendidikan menengah. Melalui aktivitas jasmani ini diharapkan tujuan pendidikan yang meliputi ranah kognitif, afektif, fisik dan psikomotorik dapat terwujud. Sekolah adalah salah satu tempat yang strategis dalam pembentukan karakter selain di keluarga dan masyarakat, melalui sekolah proses penanaman nilai-nilai karakter siswa akan diaplikasikan baik melalui kegiatan belajar mengajar, budaya sekolah, dan kegiatan pengembangan diri (Abdulloh Hamid. 2013).

Pendidikan kejuruan dan vokasi adalah pendidikan yang menuju pada proses inkulturisasi dan akulturasi yaitu proses memperadabkansuatu generasi baru masa depan yang ber-langsung di sekolah, keluarga, industri, dunia usaha, dan masyarakat terbuka yang porous (Putu Sudira, 2011:1), sehingga implementasi pendidikan karakter di SMK dapat mengupayakan terciptanya keselarasan antara karakter yang dikembangkan di sekolah dengan pembiasaan di rumah dan masyarakat. Agar pendidikan karakter dapat dilaksanakan secara optimal, pendidikan karakter bisa dilaksanakan melalui integrasi dengan mata pelajaran yang ada, salah satunya adalah mata pelajaran pendidikan jasmani olahraga kesehatan (PJOK). Namun realita di lapangan untuk mengimplementasikan pendidikan karakter di masing-masing sekolah mengalami kesulitan, karena tidak adanya standar yang jelas sehingga pendidikan karakter masih belum menemukan bentuknya, dan masih dalam batas trial and eror, namun disisi lain tidak adanya draf standar yang jelas tentang pendidikan karakter, memberikan ruang untuk mengembangkan pendidikan karakter di masing-masing satuan pendidikannya (Abdulloh Hamid. 2013).

\section{Solusi dan Target}

SMK mempunyai ciri khas yang membedakan dengan sekolah menengah atas lainnya (SMA dan MA) yaitu hubungan erat dengan dunia kerja, pada awal berdirinya SMK didesain demikian rupa untuk bekerja, melanjutkan atau wiraswasta (BMW), serta dalam pembelajarannya banyak menggunakan learning by doing. Sehingga karakteristik dan kompetensi siswa SMK harus sesuai dengan kebutuhan dunia kerja, seperti: berkarakter personal baik, berkarakter kerja kuat dan lain-lain (Abdulloh Hamid. 2013).Pendidikan kejuruan bertujuan untuk menghasilkan manusia yang produktif, yakni manusia kerja, bukan manusia beban bagi keluarga, masyarakat dan bangsanya. Manusia menjadi manusia karena bekerja. Bekerja adalah sebuah tindakan, sebuah actus, untuk menyatakan kemandirian (Abdulloh Hamid, 2013).

SMK mempunyai ciri khas tentang pendidikan karakter yaitu: pendidikan karakter kerja, sebagai pendidikan yang mempersiapkan lulusannya memiliki daya hati (heart set) kerja, baik sebagai pekerja (pegawai), bekerja sendiri (sebagai pengusaha kecil), maupun sebagai orang yang memperkerjakan orang lain. Definisi ini jelas menuntut dilakukannya restrukturalisasi, 
rekulturasi dan refigurisasi pembelajaran pada institusi-institusi pendidikan yang khususnya memang dirancang untuk menyiapkan lulusannya memasuki lapangan kerja, yaitu Sekolah Menengah Kejuruan (SMK) (Abdulloh Hamid, 2013).

\section{METODE PELAKSANAAN}

Langkah-langkah dalam pelaksanaan pengabdian ini dengan menggunakan metode Character Building by Physical Education (CBPE)

Metode yang digunakan dalam kegiatan ini meliputi:

\section{Ceramah dan presentasi dengan materi yang disampaikan dari para nara sumber dengan menggunakan makalah, power point, dan film film.}

Metode ceramah adalah sebuah metode mengajar dengan cara menyampaikan informasi serta pengetahuan melewati lisan kepada sejumlah siswa yang umumnya mengikuti pendidik secara pasif. Metode ini bisa dikatakan sebagai satu-satunya cara yang paling ekonomis untuk menyampaikan suatu informasi, dan paling efektif dalam mengatasi langkanya bahan rujukan atau literatu sesuai dengan jangkauan daya beli dan pemahaman siswa.

Penggunaan metode ceramah pada kelas dengan jumlah siswa yang relatif banyak membutuhkan teknik tersendiri, yang tentunya secara teknis akan berbeda dengan penggunaan metode ceramah pada kelas yang jumlah siswanya terbatas. Demikian pula, dengan penggunaan metode diskusi, perlu digunakan teknik yang berbeda pada kelas yang siswanya tergolong aktif dengan kelas yang siswanya tergolong pasif. Dalam hal ini, guru pun dapat berganti-ganti teknik meskipun dalam koridor metode yang sama.

\section{Diskusi dan dialog antara nara sumber dan peserta pelatihan}

Metode diskusi ialah cara mengajar yang sangat erat kaitannya dengan pemecahan suatu masalah. Metode ini umum dikenal dengan diskusi kelompok dan resitasi bersama (socialized recitation). Menurut Yamin (2012:103) Metode diskusi adalah interaksi antara siswa dan siswa atau siswa dengan guru untuk menganalisis, memecahkan masalah, menggali atau memperdebatkan topik atau permasalahan tertentu. Sedangka menurut Bahri \& Zain (2006:87) metode diskusi adalah cara penyajian pelajaran, dimana siswa-siswa dihadapkan kepada suatu masalah yang bisa berupa pernyataan atau pertanyaan yang bersifat problematis untuk dibahas dan dipecahkan bersama. Serta menurut Hamdani (2010:159) Metode diskusi adalah interaksi antarsiswa atau interaksi siswa dengan guru, untuk menganalisis, memecahkan masalah, menggali, atau memperdebabkan topik atau permasalahan tertentu.

\section{Memberikan tugas berupa identifikasi masalah oleh peserta tentang masalah yang} dihadapi.

Pemberian tugas dengan arti guru menyuruh anak didik misalnya membaca, tetapi dengan menambahkan tugas-tugas seperti mencari dan membaca buku-buku lain sebagai perbandingan, atau disuruh mengamati orang/masyarakatnya setelah membaca buku itu. Dengan demikian, pemberian tugas adalah suatu pekerjaan yang harus anak didik selesaikan tanpa terikat dengan tempat.

\section{Mengadakan diskusi dan dialog tentang solusi terhadap masalah tersebut (Problem Based Instruction)}

Problem Based Instruction (PBI) adalah suatu model pengajaran dengan pendekatan pembelajaran siswa pada masalah autentik. Masalah autentik dapat diartikan sebagai suatu masalah yang sering ditemukan siswa dalam kehidupan sehari- hari. Dengan metode Problem Based Instruction (PBI) siswa dapat dilatih menyusun sendiri pengetahuannya, mengembangkan keterampilan pemecahan masalah, mandiri serta meningkatkan kepercayaan 
diri. Selain itu dengan pemberian masalah autentik, siswa dapat membentuk makna dari bahan pembelajaran melalui proses belajar dan menyimpannya dalam ingatan sehingga sewaktuwaktu dapat digunakan lagi (Nurhadi, 2004). Dengan demikian dapat di rumuskan bahwa guru sebagai pendidik harus mampu menerapkan model pembelajaran PJOK yang bervariatif, menyenangkan, dan lebih merangsang perkembangan siswa lebih mandiri, sehingga kemampuan guru dalam memilih dan mengembangkan strategi Pembelajaran lebih meningkat yang menjadikan proses pembelajaran yang lebih baik lagi.

\section{Khalayak Sasaran}

Sasaran yang utama pada pelaksanaan pengabdian ini adalah siswa/i SMK se Pesisir Selatan, tetapi dengan terbatasnya waktu pelaksanaannya, tim pengabdi memanfaatkan para guru sebagai penerus pembicaraan dan informasi serta motor dalam pelaksanaan pendidikan karakter di sekolah.

\section{Indikator Keberhasilan}

Terjadi peningkatan pada proses pembelajaran di sekolah terutama dalam peningkatan pendidikan karakter yang saat ini sedang mengalami krisis. Peningkatan ini tentunya guru PJOK sebagai motor dalam pelaksanaan.

\section{Metode Evaluasi}

Proses evaluasi yang dilakukan masih akan terus berlanjut, sampai beberapa bulan dan bahkan tahun kedepan. Proses pendidikan karakter tidak bisa di lihat dalam jangka waktu yang beberapa hari saja. Perlu proses panjang dan perlu penanganan terus menerus.

\section{HASIL DAN PEMBAHASAN}

Karakter jujur, disiplin, sportif, tanggung jawab, dan kerjasama dapat dibangun melalui pendidikan jasmani dan olahraga. Pengembangan karakter tidak cukup melalui pengetahuan kognitif, tetapi harus dilakukan melalui tiga tahap yairu: (1) tahap pengetahuan (knowing), (2) pelaksanaan (acting), dan (3) kebiasaan (habit).Pengembangan karakter melalui Pendidikan Jasmani dan Olahraga selaras dengan pendapat yang dikemukakan oleh Lickona (1991) yang mementingkan keseimbangan antara moral knowing, moral feeling, dan moral action.Lickhona (1991) menyatakan bahwa komponen karakter terdiri atas: moral knowing, moral feeling, dan moral action. Dalam hendaknya dilakukan pengembangan komponen-komponen karakter tersebut secara seimbang dan bersama-sama (tidak hanya salah satunya). Pendekatan komprehensif Lickhona (1991:53) ini jika dimodelkan dapat digambarkan sebagai berikut:

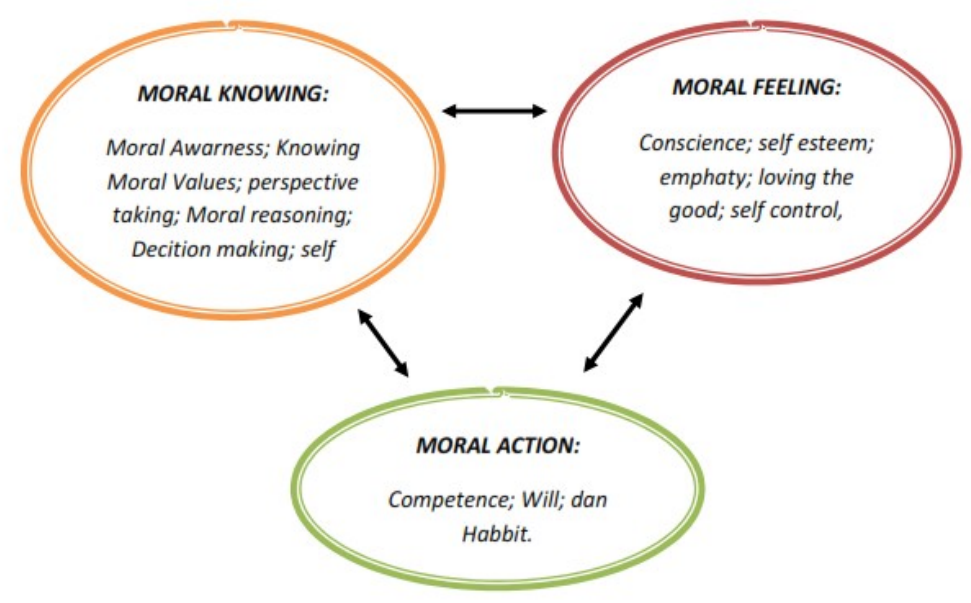




\section{Gambar 1. Pendekatan Komprehensif Lickhona Pendidikan Karakter}

Pelaksanaan pengabdian yang dilakukan dengan target para guru PJOK SMK se Pesisir Selatan berjalan dengan baik serta memperoleh hasil yang cukup memuaskan. Hasil pelaksanaan pengabdian menyatakah bahwa semau guru telah berperan aktif melakukan pendidikan karakter dalam proses pembelajaran belajar mengajar, seperti sportif, kejasama, religius dan masih banyak lagi lainnya, hal tersebut senada dengan yang dikatakan oleh Weinberg dan Gould (2007:552) mengatakan setidaknya terdapat nilai-nilai yang baik yang dapat dibentuk melalui aktivitas olahraga, antara lain: rasa kasih sayang (compassion), keadilan (fairness), sikap sportif (sport-personship), dan integritas (integrity). Ada beberapa indikator yang pengabdi lakukan untuk melihat seberapa besar guru PJOK telah melakukan pendidikan karakter di sekolah masing-masing. Hasilnya dapat dilihat pada tabel berikut ini:

Tabel 1. Hasil Pelaksanaan Pendidikan Karakter pada Mapel PJOK SMK di Pesisir Selatan

\begin{tabular}{|c|c|c|}
\hline Unsur & Penilaian & Pelaksanaan \\
\hline Rasa hormat & $\begin{array}{l}\text { - } \text { Menghormati peraturan permainan dan tradisinya } \\
\text { - } \text { Menghormati lawan bermain } \\
\text { - } \quad \text { Menghormati para ofisial } \\
\end{array}$ & $80 \%$ \\
\hline $\begin{array}{l}\text { Bertanggung } \\
\text { jawab }\end{array}$ & $\begin{array}{l}\text { - } \quad \text { Persiapkan diri sendiri untuk menjadi yang terbaik } \\
\text { - } \quad \text { Tepat waktu saat berlatih dan bermain } \\
\text { - } \quad \text { Dapat bekerja sama dengan kawan setim }\end{array}$ & $85 \%$ \\
\hline Peduli & $\begin{array}{l}\text { - } \quad \text { Bantu kawan setim untuk bermain yang terbaik } \\
\text { - } \quad \text { Mendukung kawan setim saat kacau } \\
\text { - } \quad \text { Murah hati dengan pujian; pelit dengan kritikan } \\
\text { - } \quad \text { Bermain untuk tim, bukan untuk diri sendiri }\end{array}$ & $95 \%$ \\
\hline Jujur & $\begin{array}{l}\text { - } \quad \text { Bermain sesuai dengan aturan } \\
\text { - } \quad \text { Setia pada tim } \\
\text { - } \text { Bermain bebas dari obat-obatan } \\
\text { - } \text { Mengakui kesalahan diri sendiri }\end{array}$ & $85 \%$ \\
\hline Adil & $\begin{array}{l}\text { Perlakukan pemain lain seperti perlakuan orang lain } \\
\text { - } \quad \text { Jujur dengan semua pemain, termasuk pemain yang } \\
\text { berbeda sekalipun } \\
\text { - Beri pemain lain kesempatan } \\
\text { - Bermain untuk menang dengan mengikuti peraturan }\end{array}$ & $85 \%$ \\
\hline $\begin{array}{l}\text { Menjadi } \\
\text { warga } \\
\text { masyarakat } \\
\text { yang baik }\end{array}$ & $\begin{array}{l}\text { - } \quad \text { Menjadi model (contoh) yang baik } \\
\text { - } \quad \text { Berjuang untuk yang terbaik } \\
\text { - } \quad \text { Mendorikn masukan pada olahraga } \\
\quad \text { yang baik }\end{array}$ & $80 \%$ \\
\hline
\end{tabular}

Dari hasil yang ditemukan di atas mengungkap bahwa pelaksanaan pendidikan karakter di sekolah sudah berjalan dengan baik, hanya saja perlu langkah yang kedepan untuk mengoptimalkan pelaksanaan tersebut. Sehingga PJOK benar-benar mampu menjdi solusi pemerintah untuk meningkatkan karakter anak bangsa yang saat ini sedang menjadi isu nasional karena menurunnya rasa nasionalisme, khususnya pada remaja. Di sisi lain terjadi kekhawatiran para guru untuk kedepannya, khususnya pada sekolah menengah kejuruan, 
karena pada akhir tahun 2018, pemerintah resmi menghapus mata pelajaran PJOK pada kelas XII di SMK se Indonesia. Hal tersebut tentu akan menjadi masalah nasional, di sisi lain pemerintah sedang meningkatkan kembali pendidikan karakter tetapi di sisi lain justru menghapus pembelajaran yang sudah pasti dapat mengembalikan ke arah yang lebih baik.

\section{KESIMPULAN}

Selaras dengan pernyataan Soekarno terkait dengan Nation and Character Building, Ellen G. White menyatakan bahwa Pembangunan karakter adalah usaha paling penting yang pernah diberikan kepada manusia. Pembangunan karakter adalah tujuan luar biasa dari sistem pendidikan yang benar.Pendidikan jasmani dan olahraga memiliki peran besar dalam upaya pengembangan karakter, karena kegiatan pembelajaran pendidikan jasmani melibatkan; kognitif, afektif dan psikomotor. Hal tersebut selaras dengan teori belajar gerak yang meliputi tiga tahapan, (1) kognisi, (2) asosiasi dan (3) otomatisasi. Pada bagian asosiasi inilah intervensi terhadap nilai-nilai karakter di asah.Kegiatan olahraga setiap komponen yang terlibat memiliki fungsi dan peran masing-masing. Ada pemain atau atlet, pelatih, wasit, dan penonton. Masingmasing memiliki peran yang berbeda, dan tidak ada yang tumpang tindih, misalnya menjadi pemain sekaligus wasit, atau wasit sekaligus penonton.

\section{DAFTAR PUSTAKA}

Suparmin, Mamin. 2010. Makna Psikologi Perkembangan Peserta didik. Jurnal Ilmiah SPIRIT. ISSN: 141-8319 Vol. 10. No. 2. Tahun 2010

Sriyanti, Lilik. 2011. Modul Psikologi belajar. Yogyakarta: CV. Orbittrust Corp

Jhon W. Santrock, Educational Psychology, $5^{\text {th }}$ edition (New York: McGraw-Hill Companies, 2011), h. 2

Kate M. Loewwenthal, The Psychology of Religion: A Short Intorduction (Oxford: Oneworld, 2008), h. 1

H.B. English dan A.C English., A Comprehensive Dictionary of Psychological and Psychoanalytic Terms: A Guide to Usage (New York, London and Toronto: Longmans Green, 1958), h.

Singgih, G, Setiadarma, M.P., \& Myrna, H.R.S. 1996. PsikologlOlahrga: Teori dan Praktis. Jakarta: BPK Gunung Mulya

Supriyadi. 2015. Psikologi Olahraga. Bali: Fakultas Kedokteran Universitas Undaya

Weinberg, R.S. \& Gould, D. (1995). Foundations of sport and exercise psychology. Champaign, Illinois: Human Kinetics.

Hoedaya, Danu. 2007. Kajian Psikologi Olahraga Dari Persepektif Disiplin Keilmuan. Bandung: FPOK UPI

Sudrajat, Ajat. 2011. Mengapa Pendidikan Karakter. Yogyakarta: Universitas Negeri Yogyakarta Jurnal Pendidikan Karakter, Tahun I, Nomor 1, Oktober 2011

Kementrian Pendidikan Nasional Badan Penelitian dan Pengembangan Pusat Kurikulum. 2010. Bahan Pelatihan Penguatan Metodologi Pembelajaran Berdasarkan Nilai-Nilai Budaya Untuk Membentuk Daya Saing Dan Karakter Bangsa. Pengembangan Pendidikan dan Karakter Bangsa. Jakarta: Kemendiknas

Depdiknas. Undang-undang Nomor 20 Tahun 2003 tentang Sistem Pendidikan Nasional. Jakarta: Depdiknas 
Afandi, Rifki. 2011. Integrasi Pendidikan Karakter Dalam Pembelajaran Ips di Sekolah Dasar. Universitas Muhammadiyah Sidoharjo: Fakultas Keguruan dan Ilmu Pendidikan Pedagogia Vol. 1, No. 1, Desember 2011: 85-98

NursidSumaatmadja. 2007. Konsep Dasar IPS. Jakarta: UniversitasTerbuka

Suyatno. 2009. Urgensi Pendidikan Karakter. Jakarta: Depdiknas.

Setiawan, Deny. 2013. Peran Pendidikan Karkter dalam Mengembangkan Kecerdasan Moral. UNIMED: Fakultas Ilmu Sosial Jurnal Pendidikan Karakter Tahun III, Nomor 1, Februari 2013.

Kemko Kesejahteraan Rakyat. 2010. Kebijakan Nasional Pembangunan Karakter Bangsa. Jakarta: Kemko Kesejahteraan Rakyat.

Kirschenbaum, Howard. 2000. "From Values Clarification to Character Education: A Personal Journey." The Journalof Humanistic Counseling, Educationand Development. Vol. 39, No. 1, September, pp. 4-20.

Lickona, Thomas. 1991. Educating for Character: How Our Schools can Teach Respect and Responsibility. New York:Bantan Books.

Hamid, Abdulloh. 2013. Penanaman Nilai-Nilai Karakter Siswa SMK Salafiyah Prodi TKJ Kajen Margoyoso Pati Jawa Tengah. Yogyakarta: UNY Jurnal Pendidikan Vokasi, Vol 3, Nomor

2, Juni 2013

Sudira, P. (2011). Pendidikan kejuruan dan vokasi berbasis tri hita karana. dalam (Prosiding Kongres Pendidikan, Peng-ajaran dan Kebudayaan). Yogyakarta: Pusat Studi Pancasila Universitas Gajah Mada.

Krathwohl, D.R., Bloom, B.S., and Masia, B.B. (1964). Taxonomy of educational objectives: handbookII: affective do-main. New York: David McKay Co.

Bahri, D. \& Zain, A. (2006). Strategi Belajar Mengajar. Jakarta: PT AsdiMahasatya.

Hadari, Nawawi. (2007). Metode Penelitian Bidang Sosial. Yogyakarta: Gajah Mada University Press

Hadari Nawawi. (2012). Metode Penelitian Bidang Sosial. Yogyakarta: Gadjah Mada University Press.

Hamdani. (2010). Strategi Belajar Mengajar. Bandung: Pustaka Setia

Yamin, Martinis. (2012). Desain Baru Pembelajaran Konstruktivistik. Jakarta: Referensi

Taniredja, dkk. (2011). Model-Model Pembelajaran Inovatif. Bandung: Alfabeta

Utama, Bandi. 2011. Pembentukan Karakter Anak Melalui Aktivitas Bermain Dalam Pendidikan Jasmani. Yogyakarta: Universitas Negeri Yogyakarta Jurnal Pendidikan Jasmani Indonesia Volume 8, Nomor 1, April 2011

Rosita, Lilis. 2018. Peran Pendidikan Karakter Dalam Pencapain Tujuan Pembelajaran Di Sekolah. Bandung: Universitas Wanita Internasional. Jurnal Ilmu Politik dan Komunikasi Volume VIII No. 1 / Juni 2018

Judiani, Sri. 2010. Implementasi Pendidikan Karakter di Sekolah Dasar Melalui Penguatan Pel aksanaan Kurikulum. Setditjen Manajemen Pendidikan Dasar dan Menengah, Kemendiknas Jurn al Pendidikan dan Kebudayaan, Vol. 16, Edisi Khusus III, Oktober 2010 